\title{
RESP 1630097/RJ (INFORMATIVO 603 STJ \\ - PUBLICADO EM 7 DE JUNHO DE 2017) - PROVA ILÍCITA E AUTOINCRIMINAÇÃO
}

\author{
Janaina T. Daniel Varalli*
}

\section{SINNTESE DO CASO}

O réu foi condenado, em $01^{\circ}$ grau de jurisdição a 07 anos de reclusão, em regime fechado e multa de 700 dias-multa por tráfico ilicito de entorpecentes (art. 33 da Lei 11.343/2006). A prova que baseou a condenação foi uma ligação feita pela mãe do réu durante uma abordagem policial. ${ }^{1}$

Constou dos autos que, durante a abordagem realizada em patrulhamento de rotina, o telefone celular de um dos acusados teria tocado, vindo este a atender a ligação utilizando-se do recurso "viva-voz" de seu aparelho. Os policiais, então, ouviram a conversa, na qual a mãe do acusado determinava que o filho se dirigisse à residência de ambos, para que este viesse a entregar o estupefaciente que ali existia para um indivíduo que o aguardava. Nada foi encontrado em poder do réu ou do corréu, mas após tal ligação, todos foram à residência do réu, local em que foi apreendida a substância ilícita (1,1 gramas de crack, acondicionados em 104 invólucros plásticos transparentes, que eram armazenados no interior de uma sacola plástica, escondida no interior de um buraco no colchão da cama utilizada pelo réu)

* Doutoranda em Direito pela PUC/SP. Mestre em Direitos Difusos e Coletivos pela Unimes/Santos.Pós-graduada em Direito Processual Penal pela Escola Paulista da Magistratura. Professora universitária, leciona Direito Penal e Processual Penal.

1 A integra da decisão pode ser obtida em: http://www.stj.jus.br/SCON/ jurisprudencia/toc.jsp?livre=201602602406.REG. Acesso em 26/07/2017. 
Em sede de apelação, a condenação foi revista. A defesa, e, requereu a nulidade da oitiva de testemunhas (que teria sido realizada com violação ao artigo 212 do Código de Processo Penal) e, no mérito, absolvição em razão da coação moral irresistível sofrida pelo acusado; subsidiariamente redução da pena base ao seu patamar mínimo legal, reconhecimento da atenuante da confissão, aplicação da figura do tráfico privilegiado (artigo 33§ $4^{\circ}$, lei $11343 / 06$ ) e fixação do regime aberto e da substituição da pena privativa de liberdade.

A preliminar, de ofensa ao artigo 212 do Código de Processo Penal foi rejeitada, com aplicação do princípio do máximo aproveitamento dos atos processuais, segundo expressa indicação a respeito na declaração de motivos do código processual vigente, bem como com base no princípio da instrumentalidade das formas (constatado que o ato realizado alcançou o fim pretendido)

No mérito, no entanto, reconheceu a ilegitimidade da diligência policial que culminou com a prisão do recorrente. Muito embora nada de ilícito tenha sido encontrado em poder deste durante a revista pessoal, foi sustentado pelos agentes da lei que ouviram informações comprometedoras ao implicado advindas de uma ligação telefônica recebida por este e atendida com o uso do recurso conhecido por "viva-voz". Segundo narrado pelos policiais, a interlocutora seria a mãe do acusado, solicitando que o filho retirasse o "material" que estava na residência de ambos, haja vista que lá compareceu um indivíduo quem não seria "do bem", pretendendo reaver aquele material, mas sem sucesso.

O Recurso Especial manejado pelo Ministério Público do Rio de Janeiro, que gerou a decisão ora analisada, tinha como objetivo restaurar a condenação proferida em primeiro grau, alegando a negativa de vigência aos arts. 157, caput e $\S 1^{\circ}$, 282, 283, 301 e 303, do Código de Processo Penal. 


\section{A DECISÃO DO STJ}

A decisão do STJ, que ora se analisa, foi ementada da seguinte forma:

PENAL E PROCESSUAL PENAL. RECURSO ESPECIAL. TRÁFICO DE DROGAS. PROVA OBTIDA DE CONVERSA TRAVADA POR FUNÇÃO VIVA-VOZ DO APARELHO CELULAR DO SUSPEITO. DÚVIDAS QUANTO AO CONSENTIMENTO. INEXISTENNCIA DE AUTORIZAÇÃO JUDICIAL. ILICITUDE CONSTATADA. AUTOINCRIMINAÇÃO. IMPOSSIBILIDADE. DESCOBERTA INEVITÁVEL. INOCORRÊNCIA. PLEITO ABSOLUTÓRIO MANTIDO. RECURSO ESPECIAL DESPROVIDO.

Considerando-se que nada ilicito foi encontrado em poder do réu, entendeu o Tribunal do Rio de Janeiro por absolver o acusado da imputação que lhe era feita. A única "prova" contra o mesmo foi o fato de que os policiais militares que realizaram a abordagem policial (de rotina) o compeliram a manter conversa com terceira pessoa (sua genitora) utilizando-se do recurso "viva voz" do aparelho celular.

Ocorre que houve flagrante violação ao direito constitucional à não autoincriminação, uma vez que com base nesta ligação, foram à residência do réu para apreender as substâncias ilícitas e prendê-lo em flagrante. Entendeu o STJ tratar-se de ilegalidade, uma vez que a abordagem dos policiais foi obtida de forma involuntária e coercitiva, verdadeira má conduta policial.

Muito embora seja possivel afirmar que na residência do réu havia substância ilícita entorpecente e que, pela quantidade, forma de acondicionamento e demais características se tratasse de droga destinada ao comércio ilegal, está-se diante de uma situação em que a prova está contaminada pela ilicitude. O acusado não poderia ter sido obrigado a atender a ligação e utilizar o recurso "viva voz; a atitude policial configurou clara ofensa ao direito à privacidade, ao sigilo telefônico e ao direito de não produzir provas contra si mesmo. 
Em que pese a posterior diligência policial tenha localizado a substância ilícita entorpecente na residência do acusado, as mesmas só foram localizadas em razão da já mencionada ligação telefônica ouvida pelos policiais sem autorização judicial. Aplicável ao caso a teoria dos frutos da árvore envenenada (fruits of the poisonous tree), consagrada no artigo $5^{\circ}$, inciso LVI, da Constituição Federal, que proclama a contaminação das provas, supostamente consideradas lícitas e admissiveis, se obtidas a partir de outras declaradas nulas pela forma ilícita de sua colheita.

O Recurso Especial do Ministério Público Estadual do Rio de Janeiro perante o Superior Tribunal de Justiça foi improvido, mantida a absolvição do acusado.

\section{ANÁLISE DA DECISÃO}

A alegação do Ministério Público, não acolhida pelo STJ, foi a de que a decisão absolutória proferida pelo Tribunal de Justiça do Rio de Janeiro estaria negando vigência aos artigos 157 , caput e $\S 1^{\circ}, 282,283,301$ e 303, todos do Código de Processo Penal.

Após a abordagem em que os policiais compeliram o acusado a atender com o uso do recurso "viva voz" a ligação telefônica que recebera, todos se dirigiram à casa do acusado, onde foi feita a apreensão das substâncias ilícitas e dada voz de prisão em flagrante delito. A entrada foi franqueada pela mãe do acusado, sem qualquer oposição. Muito embora se possa afirmar que esta diligência - entrada na residência, apreensão do produto ilícito e prisão - seja, em si, lícita, o problema está na origem da mesma.

Segundo o Ministério Público:

(...) não há qualquer ilicitude na conduta de policiais militares que, durante revista pessoal, terminam por ouvir conversação telefônica travada pelo investigado, na qual se inferia que este guardava em sua residência droga destinada ao comércio ilícito. A situação abordada pelo v. Acórdão, evidente encontro fortuito 
de prova, em nada se assemelha à quebra ilegal de sigilo telefônico. Com efeito, se trata de abordagem policial de rotina, em virtude de atitude suspeita, e não de investigação em curso sobre a prática de determinada atividade ilícita. Ademais, não é possivel presumir a ilegalidade na atuação policial simplesmente porque assim o quer o julgador, tecendo-se ilações sobre o motivo pelo qual teria o recorrido permitido que o policial ouvisse a conversa no sistema 'viva-voz'. Em situações em tudo semelhantes com a aqui em análise esse C.Superior Tribunal de Justiça, por meio de decisões monocráticas da lavra dos Eminentes Ministros Og Fernandez e Marco Aurélio Bellizze, já teve oportunidade de referendar a licitude da atuação policial

No entanto, o STJ entendeu que houve flagrante violação da proteção constitucional ao sigilo dos dados e das comunicações telefônicas (artigo $5^{\circ}$, XII, Constituição Federal).

Não se diga que este sigilo seja absoluto, como nenhum direito é. No entanto, a lei que regulamenta o assunto - Lei 9296/96 - estabelece claramente que

Art. $3^{\circ} \mathrm{A}$ interceptação das comunicações telefônicas poderá ser determinada pelo juiz, de oficio ou a requerimento:

I - da autoridade policial, na investigação criminal;

II - do representante do Ministério Público, na investigação criminal e na instrução processual penal. ${ }^{2}$

Assim, está bastante claro no texto legal que a interceptação telefônica só pode ocorrer mediante autorização judicial. Não sendo respeitado o sigilo ao qual tem direito o investigado ou acusado, a prova assim obtida é ilícita. A definição de Prova ilícita para Ada Pellegrini Grinover:

Por prova ilícita, em sentido estrito, indicaremos, portanto, a prova colhida infringindo-se normas ou princípios colocados pela Constituição e pelas leis, frequentemente para a prote-

2 BRASIL, LEI No 9.296, DE 24 DE JULHO DE 1996 - Regulamenta o inciso XII, parte final, do art. $5^{\circ}$ da Constituição Federal. Disponível em < http:// www.planalto.gov.br/ccivil_03/leis/L9296.htm> 
ção das liberdades públicas e dos direitos da personalidade e daquela sua manifestação que é o direito à intimidade. Constituem, assim, provas ilícitas, as obtidas com violação do domicílio (art. $5^{\circ}, \mathrm{XI}, \mathrm{da} \mathrm{CF}$ ) ou das comunicações (art. $5^{\circ}$, XII, da $\mathrm{CF}$ ); as conseguidas mediante tortura ou maus-tratos (art. $5^{\circ}$, III, da $\mathrm{CF}$ ); as colhidas com infringência à intimidade (art. $5^{\circ}, \mathrm{X}$, da $\left.\mathrm{CF}\right)$ etc. $^{3}$

O desrespeito à norma acima citada configura desrespeito ao princípio do devido legal e, por consequência, de uma garantia constitucional fundamental (conforme estabelece o artigo $5^{\circ}$ LIV da Constituição Federal, ninguém será privado da liberdade ou de seus bens sem o devido processo legal). A Constituição Federal, ressalte-se, proíbe expressamente a utilização de provas ilícitas.

O artigo 157 do Código de Processo Penal, ao qual, segundo o Ministério Público estava sendo negada vigência, estabelece:

Art. 157. São inadmissíveis, devendo ser desentranhadas do processo, as provas ilícitas, assim entendidas as obtidas em violação a normas constitucionais ou legais.

$\S 1^{\circ}$ São também inadmissiveis as provas derivadas das ilícitas, salvo quando não evidenciado o nexo de causalidade entre umas e outras, ou quando as derivadas puderem ser obtidas por uma fonte independente das primeiras.

$\S 2^{\circ}$ Considera-se fonte independente aquela que por si só, seguindo os trâmites típicos e de praxe, próprios da investigação ou instrução criminal, seria capaz de conduzir ao fato objeto da prova.

No caso em exame, no entanto, não há que se falar que não há nexo de causalidade ou que a diligência realizada na residência do réu pudesse ser obtida por uma fonte independente da escuta telefônica realizada. É notório que a

3 GRINOVER, Ada Pellegrini; GOMES FILHO, Antonio Magalhães; e FERNADES, Antônio Scarance. As nulidades no processo penal. 9. ed. São Paulo: Saraiva, 2006, p. 109. 
diligência se deu somente porque os policiais ouviram indevidamente a conversa telefônica do réu e que sem tal fato não teriam chegado à sua residência; a conversa telefônica foi o único elemento a determinar a diligência policial. Sobre a prova ilicita:

A prova ilícita significa, então, a prova obtida, produzida, introduzida ou valorada de modo contrário à determinada ou específica previsão legal. A ilicitude que acabamos de mencionar surgiria nas fases essenciais do aparecimento da prova no processo penal, a saber: (a) a da sua obtenção; (b) a da sua produção; (c) a da sua introdução no processo; e, por fim, (d) a da sua valoração pelo juiz da causa. Note-se que a idoneidade probatória ou de convencimento de uma prova nem sempre dependerá de sua validade. A prova poderá ser ilícita, ainda que comprovadamente eficaz quanto à reprodução de veracidade dos fatos (gravações ambientais etc.) (...) Ora, não se admite a prova obtida ilicitamente como meio de melhor e mais amplamente se tutelarem os direitos subjetivos normalmente em risco na fase de produção de provas. É dizer, não basta garantir direitos subjetivos como aqueles relativos à privacidade, à intimidade e à imagem $\left(\operatorname{art.} 5^{\circ}\right)$. É preciso atribuir consequências relevantes à violação deles. ${ }^{4}$

Ademais, houve violação ao princípio da não- autoincriminação, uma vez que os policiais, segundo depoimento dos próprios, "encaminharam" o réu até sua residência. Note-se, por oportuno, que o réu não foi informado de seus direitos direito e garantia do cidadão. O próprio Superior Tribunal de Justiça, em outra ocasião (HC 22.371) considerou inadmissíveis as confissões informais realizadas antes da advertência do direito ao silêncio e sem ter sido dada a oportunidade de conversar com um advogado. O direito ao silêncio está previsto no artigo $5 .^{\circ}$, LXIII da Constituição Federal e, em razão de uma interpretação teleológica, abrange o direito de não produzir prova contra si.

4 FISCHER, Douglas, PACELli, Eugênio. Comentários ao Código de Processo Penal e sua Jurisprudência, 8. ed. São Paulo: Atlas,2016, p. 352. 
$\mathrm{Na}$ decisão ora apreciada o Relator salienta que o Supremo Tribunal Federal já se manifestou sobre o direito à não incriminação, citando como exemplo a seguinte decisão:

O Estado - que não tem o direito de tratar suspeitos, indiciados ou réus, como se culpados fossem, antes do trânsito em julgado de eventual sentença penal condenatória (RTJ 176/805-806) também não pode constrangê-los a produzir provas contra si próprios (RTJ 141/512), em face da cláusula que lhes garante, constitucionalmente, a prerrogativa contra a autoincriminação. Aquele que sofre persecução penal instaurada pelo Estado tem, dentre outras prerrogativas básicas, (a) o direito de permanecer em silêncio, (b) o direito de não ser compelido a produzir elementos de incriminação contra si próprio nem de ser constrangido a apresentar provas que lhe comprometam a defesa e (c) o direito de se recusar a participar, ativa ou passivamente, de procedimentos probatórios que lhe possam afetar a esfera jurídica, tais como a reprodução simulada (reconstituição) do evento delituoso e o fornecimento de padrões gráficos ou de padrões vocais para efeito de perícia criminal (HC 96.219-MC/SP, Rel. Min. CELSO DE MELLO, v.g.). (HC 99289 / RS - Relator(a): Min. Celso de Mello Segunda Turma, publicada em 04/08/2011).

É necessário que se respeite que uma prova que dependa exclusivamente do réu só terá validade se for por ele realizada de forma voluntária e consciente, sem qualquer coação ou fraude.

Como se não bastassem as disposições legais previstas na Constituição Federal e Código de Processo Penal pátrios, os documentos internacionais também se preocupam em garantir que ninguém seja julgado sem observância do devido processo legal e que seja respeitado o direito à não incriminação. O Pacto Internacional sobre Direitos Civis e Políticos, (promulgado pelo Decreto 592/1992) prevê em seu artigo 14.3, g:

Todas as pessoas são iguais perante os tribunais e as cortes de justiça. Toda pessoa terá o direito de ser ouvida publica- 
mente e com devidas garantias por um tribunal competente, independente e imparcial, estabelecido por lei, na apuração de qualquer acusação de caráter penal formulada contra ela ou na determinação de seus direitos e obrigações de caráter civil. A imprensa e o público poderão ser excluídos de parte da totalidade de um julgamento, quer por motivo de moral pública, de ordem pública ou de segurança nacional em uma sociedade democrática, quer quando o interesse da vida privada das Partes o exija, que na medida em que isso seja estritamente necessário na opinião da justiça, em circunstâncias específicas, nas quais a publicidade venha a prejudicar os interesses da justiça; entretanto, qualquer sentença proferida em matéria penal ou civil deverá torna-se pública, a menos que o interesse de menores exija procedimento oposto, ou processo diga respeito à controvérsia matrimoniais ou à tutela de menores.

(...)

3. Toda pessoa acusada de um delito terá direito, em plena igualmente, a, pelo menos, as seguintes garantias:

(...)

g. De não ser obrigada a depor contra si mesma, nem a confessar-se culpada. ${ }^{5}$

A Convenção Americana sobre Direitos Humanos, também conhecida como Pacto de São José da Costa Rica (promulgada em território nacional pelo Decreto 678/1992), dispõe em seu artigo $8^{\circ}, 2$, g:

2. Toda pessoa acusada de delito tem direito a que se presuma sua inocência enquanto não se comprove legalmente sua culpa. Durante o processo, toda pessoa tem direito, em plena igualdade, às seguintes garantias mínimas:

(...)

g. direito de não ser obrigado a depor contra si mesma, nem a declarar-se culpada; ${ }^{6}$

5 BRASIL, Decreto 592/92. Disponivel em < http://www.planalto.gov.br/ccivil_03/decreto/1990-1994/d0592.htm> Acesso em $01 / 08 / 2017$.

${ }^{6}$ BRASIL. Decreto 678/92. Disponivel em <http://www.planalto. gov.br/ccivil_03/decreto/d0678.htm>Acesso em 01/08/2017 
Diante do exposto nos documentos internacionais acima transcritos, das disposições constitucionais previstas no artigo $5^{\circ}$, II, XII, LIV e LVI, LXIII, além do artigo 157 do Código de Processo Penal, fica clara a violação do devido processo legal, do sigilo das comunicações e que o acusado foi compelido a produzir prova contra si, o que contaminou a prova posteriormente obtida e que portanto, não pode ser utilizada.

Muito embora saibamos que a criminalidade deva ser combatida e que o tráfico ilícito de drogas é um problema de segurança pública e de saúde e, não se pode admitir exceções ao devido processo legal, basilar para a existência e manutenção do Estado Democrático de Direito.

\section{REFERENCIAS}

BRASIL, SUPERIOR TRIBUNAL DE JUSTIÇA. REsp 1630097/RJ (INFORMATIVO 603 STJ - Publicado em 7 de junho de 2017). Disponível em $<\underline{\text { http: } / /}$ www.stj.jus.br/SCON/jurisprudencia/toc.jsp?livre $=201602602406$. REG $>$ Acesso em 26/07/2017.

BRASIL, Constituição Federal. Disponivel em:

< http://www.planalto.gov.br/ccivil 03/constituicao/constituicao.htm>

BRASIL, Código de Processo Penal. Disponível em:

< http://www.planalto.gov.br/ccivil 03/decreto-lei/Del3689Compilado.htm>

BRASIL, Decreto 592/92. Disponível em:

< http://www.planalto.gov.br/ccivil 03/decreto/1990-1994/d0592.htm> Acesso em 01/08/2017.

BRASIL. Decreto 678/92. Disponivel em:

<http://www.planalto.gov.br/ccivil_03/decreto/d0678.htm> Acesso em $01 / 08 / 2017$

BRASIL. Lei 9.296/1996 - Regulamenta o inciso XII, parte final, do art. $5^{\circ}$ da Constituição Federal. Disponível em

< http://www.planalto.gov.br/ccivil_03/leis/L9296.htm>

FISCHER, Douglas, PACELLI, Eugênio. Comentários ao Código de Processo

Penal e sua Jurisprudência. 8. ed. São Paulo: Atlas, 2016. 
GRINOVER, Ada Pellegrini; GOMES FILHO, Antonio Magalhães; e FERNANDES, Antônio Scarance. As nulidades no processo penal. 9. ed. São Paulo: Saraiva, 2006.

MEndroni, Marcelo Batlouni. Provas no Processo Penal: Estudo sobre a Valoração das Provas Penais. 2. ed. São Paulo: Atlas, 2015.

\section{RECURSO ESPECIAL No 1.630.097 - RJ (2016/0260240-6)}

RELATOR: MINISTRO JOEL ILAN PACIORNIK

RECORRENTE: MINISTÉRIO PÚBLICO DO ESTADO DO RIO DE JANEIRO ADVOGADO: DEFENSORIA PÚBLICA DO ESTADO DO RIO DE JANEIRO

\section{EMENTA}

PENAL E PROCESSUAL PENAL. RECURSO ESPECIAL. TRÁFICO DE DROGAS. PROVA OBTIDA DE CONVERSA TRAVADA POR FUNÇÃO VIVA-VOZ DO APARELHO CELULAR DO SUSPEITO. DÚVIDAS QUANTO AO CONSENTIMENTO. INEXISTÊNCIA DE AUTORIZAÇÃO JUDICIAL. ILICITUDE CONSTATADA. AUTOINCRIMINAÇÃO. IMPOSSIBILIDADE. DESCOBERTA INEVITÁVEL. INOCORRÊNCIA. PLEITO ABSOLUTÓRIO MANTIDO. RECURSO ESPECIAL DESPROVIDO.

1. O Tribunal de origem considerou que, embora nada de ilícito houvesse sido encontrado em poder do acusado, a prova da traficância foi obtida em flagrante violação ao direito constitucional à não autoincriminação, uma vez que aquele foi compelido a reproduzir, contra si, conversa travada com terceira pessoa pelo sistema viva-voz do celular, que conduziu os policiais à sua residência e culminou com a arrecadação de todo material estupefaciente em questão. 2. Não se cogita estar diante de descoberta inevitável, porquanto este fenômeno ocorre quando a prova derivada seria descoberta de qualquer forma, com ou sem a prova ilícita, o que não se coaduna com o caso aqui tratado em que a prova do crime dependeu da informação obtida pela autoridade policial quando da conversa telefônica travada entre o suspeito e terceira pessoa. 3. O relato dos autos demonstra que a abordagem feita pelos milicianos foi obtida de forma involuntária e coercitiva, por má conduta policial, gerando uma verdadeira autoincriminação. Não se pode perder de vista que qualquer tipo de prova contra o réu que dependa dele mesmo só vale se o ato for feito de forma voluntária e consciente. 4. Está-se diante de situação onde a prova está contaminada, diante do disposto na essência da teoria dos frutos da árvore envenenada (fruits of the poisonous tree), consagrada no art. $5^{\circ}$, inciso LVI, da Constituição Federal, que proclama a nódoa de provas, 
supostamente consideradas licitas e admissíveis, mas obtidas a partir de outras declaradas nulas pela forma ilicita de sua colheita. 5. Recurso especial desprovido.

\section{ACóRDÃo}

Vistos, relatados e discutidos os autos em que são partes as acima indicadas, acordam os Ministros da Quinta Turma do Superior Tribunal de Justiça, por unanimidade, conhecer do recurso, mas lhe negar provimento. Os Srs. Ministros Felix Fischer, Jorge Mussi, Reynaldo Soares da Fonseca e Ribeiro Dantas votaram com o Sr. Ministro Relator.

Brasília (DF), 18 de abril de 2017(Data do Julgamento)

MINISTRO JOEL ILAN PACIORNIK

Relator 